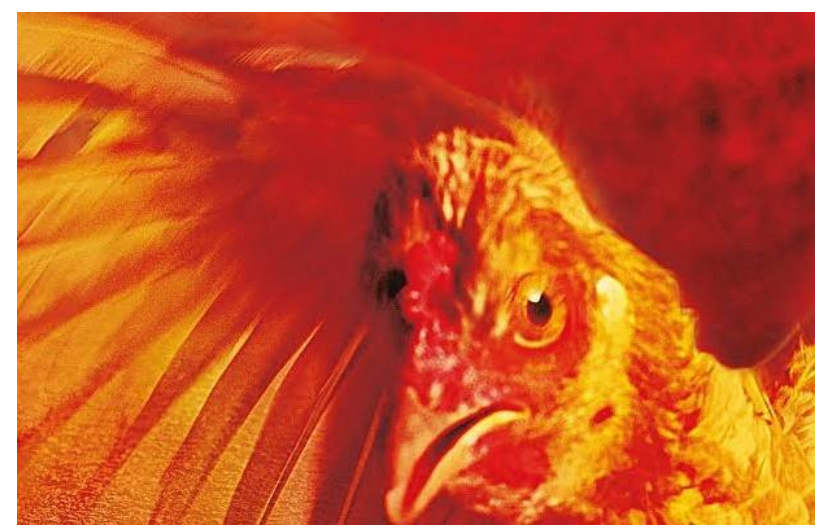

\title{
Territórios de exceção: poder, espaço urbano, literatura
}

Territories of exceptios: power, urban space, literature

\author{
Luca Fazzini ${ }^{1}$ \\ https://orcid.org/0000-0002-7210-385
}

\section{Resumo:}

Levando em consideração as reflexões sobre "biopolítica", de Michel Foucault, e "poder soberano", de Giorgio Agamben, assim como as análises das dinâmicas coloniais na contemporaneidade, desenvolvidas por Achille Mbembe, o presente ensaio investiga os múltiplos mecanismos violentos do poder nas periferias urbanas brasileiras. Através da análise do romance Cidade de Deus, de Paulo Lins, o objetivo do artigo é questionar o papel da escrita como instrumento de sobrevivência e resistência perante a condição de "vida nua", desprovida dos direitos de cidadania, à qual o corpo negro e periférico encontra-se submisso.

Palavras-chave: Violência urbana. Biopolítica. Estado de exceção. Estudos pós-coloniais.

\begin{abstract}
:
Taking into account the consideration made by Michel Foucalt and Giorgio Agamben on "biopolitics" and "sovereignty", as well as Achille Mbembe's analysis of contemporary colonial dynamics, this essay aims to investigate the diverse violent mechanisms of power in the brazilian urban outskirts. Through an analytical reading of Paulo Lins' novel Cidade de Deus, the goal of the article is to reflect on the role of writing as a mean of survival and resistance to the condition of "naked life"- a life deprived of rights and citizenship-to which the black and suburban body is subjugated.
\end{abstract}

Keywords: Urban violance. Biopolitics. State of exception. Post-colonial studies.

\footnotetext{
${ }^{1}$ Professor no Istituto Italiano di Cultura - Rio de Janeiro (IIC-RJ), doutorando no âmbito do programa em Literatura, Cultura e Contemporaneidade da Pontifícia Universidade Católica do Rio de Janeiro (PUCRio).E-mal: lucafazz@ hotmail.it
} 


\section{Interrogar a violência: dinâmicas coloniais nas cidades contemporâneas.}

Dante acorda no outro lado do rio Aqueronte. Na margem oposta, Caronte carrega no seu barco as almas danadas para a travessia. Um terremoto, acompanhado por uma luz avermelhada tinha deixado o poeta no chão, desmaiado. Dante desperta na escuridão infernal depois de ter atravessado, sem consciência nem memória, o rio que separa o mundo dos vivos do mundo dos mortos. Virgílio, guia de Dante nos círculos infernais, tenta esclarecer-lhe a situação, introduzi-lo ao novo cenário, mas o poeta viajante o interrompe. Virgílio aparece de rosto pálido, a voz trémula. Dante percebe ter alguma sensação estranha, talvez seja o medo, afetando a segurança do seu nobre acompanhante. Os dois estão próximos a ingressar no limbo, e Virgílio manifesta no seu rosto a angústia de quem está prestes a entrar no lugar da sua própria condenação: aí estão as almas de quem morreu virtuoso e sem pecado, porém não batizado, de quem não conheceu a salvação, quem não tem direito de acessar ao paraíso porque embora o mereça sua alma não aceitou a graça de Deus. Dentro da tradição cristã, esse é o lugar designado para o outro.

Antes mesmo das diversas penas e virtudes que irão atravessar o caminho de Dante dentro da sua Comédia, está-se perante uma grande linha imaginária que divide por um lado quem, em vida, conheceu a graça de Deus, podendo portanto ser julgado na hora da morte dentro das lógicas divinas e quem, por outro lado, não tem esse direito, pois não pertence a esse mundo - é o caso do próprio Virgílio, assim como de Homero, Horácio e Ovídio, entre outros, poetas da tradição grega e latina mortos antes do cristianismo que Dante encontrará no limbo.

Em um dos seus primeiros filmes, Mamma Roma, de 1962, o cineasta e poeta italiano Pier Paolo Pasolini irá procurar os versos da Comédia de Dante aqui em epígrafe: o incipit do canto IV do Inferno, o acordar de Dante na margem do Aqueronte e o empalidecer de Virgílio ao ingressar no limbo. Está nas cenas finais do filme. Ettore, o jovem protagonista, encontra-se deitado na cama de um hospital penitenciário, onde está preso, queimando em febre, por ter tentado roubar um pequeno rádio. Ettore encontrará a morte agarrado a uma cama de madeira, onde será deixado morrer na ausência da mãe, dos médicos e da própria lei, numa cena cuja perspectiva da câmera remete de forma clara para a têmpera sobre tela de Andrea Mantegna, Lamentação sobre o Cristo Morto (1475/1478). Filho de Mamma Roma, uma ex-prostituta que ao mudar de vida tenta perspectivar para o filho uma existência pequeno-burguesa, Ettore pertence às classes 
populares, ao subproletariado urbano. Enquanto ele está deitado na cama do hospital, tendo alucinações e delírios causados pela febre, outros quatros presos, também internados no mesmo quarto do hospital, conversam entre eles num tom irônico e zombeteiro. Um deles costuma decorar os cantos da Comédia de Dante e provocado pelos risos dos outros começa a declarar-lhes o incipit do Canto VI do inferno: "Rompeu o profundo sono em minha mente/um trovão que me fez estremecer" (ALIGHIERI, 2017a, p. 43)

Pronunciados numa espécie de limbo, a cela de um hospital penitenciário- que não é ainda cadeia, mas tampouco indicia liberdade - , num italiano bárbaro, por presos que como Ettore que pertencem às classes populares, à marginalidade urbana, os versos da Comédia permitem uma aproximação entre essas figuras de excluídos e as que Dante encontra ao longo do Canto IV. Os presos de Pasolini não foram batizados pelo capital, não pertencem ao modelo burguês que irá se impor na Itália do boom econômico da década de sessenta e por isso só podem ficar excluídos dentro do limbo da própria miséria até a hora da morte. Numa perspectiva mais ampla, no contexto urbano no qual Pasolini ambienta os seus primeiros filmes e romances, a prisão e a periferia são de fato o limbo, onde estão condenados todos aqueles indivíduos vulneráveis que não existem para Deus e para o capital, sem nenhum direito, proprietários apenas do próprio corpo. Corpos atormentados pela violência de uma existência mísera, pela fome constante que marca o ritmo de dias e dias passados tentando satisfazer as necessidades físicas dessa única propriedade, que é justamente o próprio corpo, num ciclo sem fim composto por três momentos repetidos: fome, crime, temporária satisfação.

Pode-se ler assim também a outra referência à Comédia de Dante feita por Pasolini no seu primeiro filme, Accattone, de 1961. A ambientação é aproximativamente a mesma que a de Mamma Roma. O protagonista é o mesmo subproletariado romano. O filme abrese tendo como epígrafe os versos do Canto V do purgatório: "o anjo de Deus tomou-me, e o do Inferno:/ ‘Tu, do Céu, por que o pilhas?’”. Como no Canto IV do Inferno onde as almas estavam presas no limbo, sem ter acesso ao inferno, também no V do Purgatório está-se num lugar de exceção, o antipurgatório. É este o canto do corpo, do corpo atormentado, o dos mortos de morte violenta, como figura central.

Consideradas em conjunto, as duas referências ao universo dantesco que Pier Paolo Pasolini procura ao encenar a existência dos marginalizados da cidade oferecem uma perspectiva prolífica para refletir acerca do espeço urbano e das suas dinâmicas de exclusão. O subalterno, o marginal, aparece como um corpo torturado pelas violências e 
pela fome endêmica, vivenciando uma constante exceção enquanto corpo fora da norma ${ }^{2}$ - em Pasolini a normatividade na atual sociedade de consumo é a estabelecida pelo modelo burguês -, não contemplado nem pela lei, como os mortos sem batismo do canto IV do Inferno de Dante. Está-se perante a vida nua (zoé em grego, diferente do conceito de biós que se refere à vida integral, à praxis do sujeito) -conceito chave na série de obras Homo Sacer, de Giorgio Agamben: mera existência biológica cuja entrada na esfera da polis marcou, para Michael Foucaut (2005) o começo da época moderna, enquanto para Agamben significa principalmente que o Estado de Exceção, condição própria à vida nua, tornou-se, na contemporaneidade, a regra. ${ }^{3}$ As trajetórias pessoais das personagens dos filmes de Pier Paolo Pasolini aqui mencionados podem, num certo sentido, ser estimulantes para pensar a atualidade como Estado de Exceção. Com certeza evidenciam como dentro do espaço da cidade - locus que considero fulcral para pensar a contemporaneidade -, nas dinâmicas excludentes e violentas que fazem parte do seu cotidiano, em diferentes momentos e situações, a vida apareça em toda a sua nudez. Sem amparos, na sua fragilidade e vulnerabilidade.

De fato, uma panorâmica abrangente sobre a organização das sociedades contemporâneas, a partir de uma perspectiva espacial, torna visível a relevância das metrópoles, dos grandes conglomerados urbanos: mais do 50\% da população global vive, atualmente, nas grandes cidades espalhadas em cada canto do globo, e tal percentagem parece destinada a aumentar, seguindo as rotas traçadas pelo fluxo ininterrupto de populações migrantes, que visam exercer o próprio "direito à cidade" - retomando uma célebre expressão de Henri Lefebvre (2003). Todavia, os sonhos ligados a uma visão utópica do espaço urbano, considerado lugar das oportunidades, das perspectivas de sucesso e, enfim, do futuro, revelam-se logo ilusões perante à crua realidade: segundo os dados discutidos durante um encontro patrocinado pela ONU em Istambul, no 1996, o número de desabrigados estaria em constante aumento. Apenas nos países chamados “em

\footnotetext{
${ }^{2}$ É importante sublinhar aqui que a norma, a normatividade, para Michel Foucault circula entre duas esferas do poder, a disciplinar e a reguladora, na medida que pode ser aplicada tanto a um corpo quanto à população. (FOUCAULT, 2005)

${ }^{3}$ Segundo as reflexões de Michel Foucault na origem da modernidade ocidental estaria a cultura política do corpo. Na modernidade a vida começa a ser considerada produtiva e útil pelo poder. A política passaria, então, a governar os corpos e regulamentar a própria vida, isso é: “deixar morrer ou fazer viver" já que o poder moderno, segundo Foucault, "desconhece a morte”. A política moderna seria então uma biopolítica enquanto é uma política que gerencia a vida.
} 
desenvolvimento" ou do "terceiro mundo" - expressões usadas durante os encontros aproximativamente 95 milhões de jovens e crianças morariam na rua. ${ }^{4}$

As metrópoles contemporâneas são, efetivamente, lugares onde se tornaria mais evidente a terrível desigualdade social que acompanha o desenvolvimento econômico dos Estados-nações e do capitalismo global. Em "Violência e Conflito nas Grandes Cidades Contemporâneas" - artigo publicado no âmbito do VIII Congresso Luso-Afro-Brasileiro de Ciências Sociais - Gilberto Velho escreve: "as grandes cidades [...] têm se apresentado como a expressão mais aguda e complexa dessa problemática, em que se mistura riqueza, desigualdade, progresso tecnológico, analfabetismo, desemprego, ressentimento, tensão social e conflitos de toda ordem" (VELHO, 2006). Cercadas por slums ou por vastas periferias, lugares símbolos da marginalização social, mas também concretos, non lieu regiões de pobreza enquanto frequentemente abrigos instáveis e temporários de sujeitos em deslocamento, a metrópole não atende às necessidades dos moradores e, nas dinâmicas de exclusão/inclusão, acaba reproduzindo as lógicas racistas que caracterizaram a modernidade colonial ocidental. De fato, considerando as análises e as estatísticas apresentadas no relatório Mapa da Violência 2016, de Julio Jacobo Waiselfisz, os contextos que mais sofreram as marcas de um passado colonial, como as Américas e a África, são os que apresentam as taxas mais altas de homicídios por armas de fogo: segundo as estatísticas, os quinze países com um maior número de homicídios ocorridos por ano, situam-se todos na América do Sul e na América Central, enquanto para encontrar países da Europa Ocidental é preciso chegar às posições $49^{\circ}, 54^{\circ}$ e $55^{\circ}$, ocupadas respetivamente por Bélgica, Itália e Portugal, todos com uma taxa de homicídios mais que duzentas vezes inferior à de Honduras, país que lidera a classificação. Considerando apenas as mortes ocorridas no Brasil, principal objeto de análise do Mapa da violência, as estatísticas evidenciam que 94\% dos óbitos sejam relativos a sujeitos de sexo masculino e que o 58\% das vítimas tenham entre 15 e 29 anos. Uma média altíssima considerando que a essa faixa etária corresponde apenas o $26 \%$ da população brasileira. Em termos raciais, o Mapa apresenta mais um dado alarmante e extremamente significativo para pensar justamente a herança da época colonial: "a vitimização negra no país que, em 2003, era de 71,7\% (morrem, proporcionalmente,

\footnotetext{
${ }^{4}$ Estes dados encontram-se no artigo "A Cidade, a Literatura e os Estudos Culturais: do Tema ao Problema", de Renato Cordeiro Gomes, publicado pela revista Ipotesi: revista de estudos literários, V.3, N.2 da UFJF e referem-se ao painel "Habitat 2" discutido durante o encontro organizado pela ONU em 1992 na capital turca.
} 
71,7\% mais negros que brancos), pula para 158,9\%, em 2014” (WAISELFISZ, 2016, P.60). ${ }^{5}$

No artigo já mencionado, o antropólogo brasileiro Gilberto Velho aponta as mudanças sociais devidas à modernização e à globalização -veja-se o individualismo exasperado e o hedonismo caraterístico da sociedade de consumo -como uma possibilidade de leitura do fenômeno espantoso da violência urbana no Brasil contemporâneo. Segundo ele, a lógica desigual e hierarquicamente controlada do sistema colonial e escravagista, permitia "mínimas expectativas de reciprocidade" (VELHO, 2004, p. 5) capazes de garantir uma ordem nos "valores" e nas "relações sociais" - embora esta ordem não garantisse nenhuma tolerância perante qualquer ameaça ao status quo. Para Velho "à medida que o individualismo foi assumindo formas mais agonísticas e que a impessoalidade foi, progressivamente, ocupando espaços antes caracterizados por contatos face to face, a violência física foi se rotinizando, deixando de ser excepcional, para se tornar uma característica cotidiana" (VELHO, 2004, p.7).

A leitura do antropólogo brasileiro aparece sem dúvida significativa para pensar a violência urbana a partir das mudanças operadas pelo consumismo moderno e pela globalização - inclusive o tráfico internacional de armas e de droga que sustentam a organização de novas formas de criminalidade -, e embora falte uma qualquer menção importante à raça das vítimas, coincide com as estatísticas referidas, quando afirma que esta atinge sobretudo a população jovem e pobre (VELHO, 2004, p.7).

Todavia, considerando justamente os alvos principais da violência e as estratégias do poder para supostamente tentar contê-la, como a constante repressão policial, seria possível evidenciar a continuidade visível das dinâmicas do tempo colonial e escravista na contemporaneidade, mais do que as diferenças e as roturas com o passado sublinhadas pelo antropólogo.De fato, a violência física e o conflito sempre foram elementos do cotidiano, mesmo durante a "ordem" estabelecida pela exploração colonial, não se tornando, portanto, peculiaridade da contemporaneidade. No primeiro capítulo de $O s$ condenados da terra, Frantz Fanon descreve justamente a violência na colônia, e suas consequências ao colonizado, considerando-a como base da organização social e espacial da colônia.

\footnotetext{
${ }^{5}$ Com a definição de Negro considera-se, no artigo, os não-brancos.
} 
Lê-se em Fanon:

O mundo colonizado é um mundo cindido em dois. A linha divisória, a fronteira, é indicada pelos quartéis e delegacias de polícia. Nas colônias o interlocutor legal e institucional do colonizado, o porta-voz do colono e do regime de opressão é o gendarme ou o soldado. [...] Nos países capitalistas, entre o explorado e o poder interpõe-se uma multidão de professores de moral, de conselheiros, de "desorientadores". Nas regiões coloniais, ao contrário, o gendarme e o soldado, por sua presença imediata, por suas intervenções diretas e frequentes, mantêm contato com o colonizado e o aconselham, a coronhadas ou com explosões de napalm, a não se mexer. Vê-se que o intermediário do poder utiliza uma linguagem de pura violência. (FANON, 1961, p.28)

Esse contato constante entre as camadas populares mais carentes e o braço armado do poder, assim como a falta dos direitos básicos do cidadão - como o acesso a infraestruturas funcionais, educação e saúde - são de fato condições ainda frequentes nos bairros mais carentes das metrópoles contemporâneas, tanto no hemisfério norte quanto no hemisfério sul do globo, bem longe de serem resolvidas.

Considerando o caso brasileiro e, em particular, o contexto urbano da cidade do Rio de Janeiro, seria possível ver como, em situações específicas, a linguagem de pura violência continua sendo a utilizada pelo poder nas "periferias" urbanas. Como exemplo pertinente pode-se considerar a política de pacificação das favelas cariocas operada através das Unidades de Polícia Pacificadora (UPP), apresentada em 2008 pelo governador Sérgio Cabral, com o intuito de estabelecer o controle do Estado em algumas favelas dominadas por traficantes de droga. O projeto inicial previa fundamentalmente duas etapas: a primeira de caráter militar, com as chamadas "Operações Militares em Área Urbana" (OMAU), a segunda social, com a criação de escolas, creches e postos de saúde. Enquanto centenas de policiais e militares, auxiliados por helicópteros, M113 anfíbios da Marinha brasileira e pelos tristemente famosos "Caveirões" do BOPE ocuparam as maiores favelas da América do Sul, como a Rocinha e o Complexo do Alemão, nada de análogo foi feito para melhorar as condições de vida e de cidadania dos moradores.

Instalando unidades da Policia Militar em áreas historicamente hostis em vez de escolas e postos de saúde, o "gendarme e o soldado" tornaram-se -ou continuam sendo únicos interlocutores possíveis para toda aquela população que vive nas condições mais precárias. População formada por trabalhadores de baixa renda inseridos na divisão social do trabalho em posições marginais (QUEIROZ RIBEIRO, 2001), em sua maioria negros e migrantes provenientes dos Estados mais pobres do país: 
muitas áreas do espaço que hoje é recoberto pela cidade do Rio de Janeiro foram ocupadas por comunidades negras, seja à época da escravidão, seja como estratégias de sobrevivência numa sociedade que, abolindo a escravidão, não democratizou o acesso à terra, e ainda quis fazer a higienização/branqueamento [...]. O racismo é uma componente importante do nosso processo de conformação territorial. Com as migrações, que se intensificam com a interligação do espaço Brasileiro, sobretudo após a abertura da rodovia Rio-Bahia, nos anos 1930, uma vaga de migrantes nordestinos veio se juntar aos pobres urbanos "quase todos pretos" que por aqui já existiam. (PORTOGONÇALVES, SILVA, 2016, p. 73)

Dentro desta lógica, pode-se ler o percentual alarmante de jovens negros mortos por armas de fogo, assim como os números relativos aos homicídios devidos às ações polícias, como uma continuação dos paradigmas coloniais na contemporaneidade urbana. Tal herança, assim como os processos de modernização evidenciados por Gilberto Velho, fazem da metrópole um espaço de conflito, um lugar distópico onde fracassa qualquer expectativa de afirmação pessoal para quem se encontra na margem.

Como a marginalidade representada por Pier Paolo Pasolini nos filmes de ambientação romana, está-se perante a vida na sua total nudez, despojada dos seus direitos básicos de cidadania. A intervenção militar, o uso do exército e do armamento pesado, geralmente reservado aos contextos de ocupação militar fora das fronteiras nacionais ou à defesa das próprias fronteiras nacionais contra a invasão de um inimigo que vem de fora aponta para um deslize no próprio campo de atuação da força militar, do contexto militar da guerra para o da sociedade civil e do cotidiano. Está-se diante de uma medida excepcional, perante aquilo que Giorgio Agamben define de "Estado de Exceção", ou seja, a suspenção do direito do cidadão, justificada pela ideia segundo a qual a partir do momento em que um indivíduo ou um grupo populacional tornar-se-ia uma ameaça para o Estado, o poder poderia tomar todas aquelas medidas consideradas como necessárias as não incluídas dentro da norma jurídica -, inclusive as de matar (AGAMBEN, 2003).

O direito de "fazer morrer ou deixar viver" seria, tanto para Michel Foucault (2005) quanto para Giorgio Agamben (2003) - que desenvolve suas reflexões sobre a vida nua tendo como ponto de partida as considerações de Annah Arendt e do próprio Foucault - a caraterística do poder soberano enquanto um biopoder, ou seja, um poder que age sobre a vida e sobre a morte dos indivíduos. Neste sentido, o Estado de Exceção vincula-se profundamente ao biopoder, ou poder soberano, enquanto só dentro de um sistema de exceção seria juridicamente admissível tirar a vida de uma pessoa ou de um predeterminado grupo populacional (FOUCAULT, 2005). 
No entanto, as análises de Foucault e de Agambem diferem em um ponto fulcral: se para o filosofo francês esses mecanismos caracterizaram momentos peculiares, excepcionais da modernidade política do ocidente - que visa a perpetuação da vida disciplinada e regulamentada -, como foi o caso dos governos totalitários e sobretudo do nazismo, para Giorgio Agamben a prática moderna da democracia, que faz com que em determinados momentos o Estado de Direito seja suspenso de maneira "legal", não difere em nada das práticas dos sistemas totalitários, sendo portanto o Estado de Exceção a norma e o campo paradigmático da vida moderna.

No seu livro Homem sacer: o poder soberano e a vida nua o filosofo italiano traz como exemplo dessa vida nua a figura do refugiado enquanto indivíduo sem direitos de cidadania, homem deslocado para um determinado espaço não-lugar, - os tantos campos para refugiados que se proliferam nos vários cantos do mundo - cuja sobrevivência vai sendo garantida por organizações humanitárias que cuidam das necessidades básicas daqueles corpos cuja existência política foi cancelada pelas guerras, pelo imperialismo, pela falta de condições básicas de subsistência. Deste modo, de acordo com Walter Benjamin, referência constante no pensamento de Agamben, pode-se, de fato, concluir que "a tradição dos oprimidos nos ensina que o ‘estado de exceção' em que vivemos é na verdade a regra geral. (BENJAMIN, 1994, p. 226)

Voltando para o contexto brasileiro, em particular o contexto urbano da cidade do Rio de Janeiro é possível ver como, além das chamadas “Operações Militares em Áreas Urbanas”, que levaram à instalação das UPP, a suspensão da ordem jurídica, que permite ao poder soberano estabelecer-se sobre a vida nua continua sendo uma prática ordinária. A própria instituição da Policia Militar, à qual cabe, segundo o artigo 144 da Constituição, a função de policiamento ostensivo ou preventivo, traz no seu nome um indício do lugar ambíguo que lhe foi conferido, no meio de um campo de atuação que pertence à organização do estado de direito - o de proteção e tutela dos direitos dos cidadãos e de cidadania, tarefa que cabe à polícia - e outro típico do estado de exceção, ou seja, o uso da força e da violência - isto é, o poder sobre a vida nua - para a resolução dos conflitos, tarefa estritamente militar. No artigo "Por que tem sido tão difícil mudar as polícias?" (2015) o antropólogo Luiz Eduardo Soares, depois de salientar as continuidades no autoritarismo e no uso da força, entre o modelo policial durante a ditadura militar e a atualidade, evidencia as consequências no plano psicocultural dessa posição ambígua dentro do modelo jurídico ocupada pela polícia militar. Escreve Soares: 
Um híbrido psicocultural que faz com que muitos profissionais tendam a oscilar entre dois eixos gravitacionais do ponto de vista axiológico: de um lado, o repertório bélico, que valoriza o heroísmo, a lealdade, a coragem física, o confronto; de outro, o código do serviço público, que valoriza os direitos e o respeito à cidadania, assim como a fidelidade à Constituição e a competência na promoção de resultados compatíveis com a democracia. (SOARES, 2015, p.31)

Essa duplicidade, dupla função, dupla consciência intrínseca no próprio nome da corporação, que oscila entre o Estado de Direito democrático e o Estado de Exceção, manifesta-se de forma evidente em duas tipologias de abordagem e intervenção, duas condutas diferentes relacionadas ao lugar de atuação da Polícia Militar: de um lado os bairros mais abastecidos, da classe média ou alta (o asfalto); de outro lado as periferias urbanas e as favelas (os morros). Essas ultimas consideradas como sendo território do "inimigo", que precisa ser ocupado e conquistado: “corporações militares tendem a ensejar culturas afetas à violência, cujo eixo é a ideia de que segurança implica guerra contra o "inimigo". Não raro essa figura é projetada sobre o jovem pobre e negro." (SOARES, 2015, p.30)

Como refere Michel Foucault no texto já mencionado, a práxis do biopoder de “fazer morrer ou deixar viver”, caraterística do poder soberano enquanto poder sobre os corpos, para se aplicar à população dentro do espaço jurídico ambíguo do Estado de Exceção, precisa encontrar um alvo, vulgarmente considerado de 'inimigo'. "Como exercer o poder da morte, como exercer a função da morte, num sistema político centrado no biopoder?" (FOUCAULT, 2005, p. 304) pergunta-se Foucault. Para o filosofo francês, a resposta está na raça e no racismo:

Tirar a vida, o imperativo da morte, só é admissível, no sistema do biopoder, se tende não à vitória sobre os adversários políticos, mas à eliminação do perigo biológico e ao fortalecimento, diretamente ligado a essa eliminação, da própria espécie ou raça. A raça, o racismo, é a condição de aceitabilidade de tirar a vida numa sociedade de normalização. Quando vocês têm uma sociedade de normalização, quando vocês têm um poder que é, ao menos em toda sua superfície e em primeira instância, em primeira linha, um biopoder, pois bem, o racismo é indispensável como condição para poder tirar a vida de alguém, para poder tirar a vida dos outros. A função assassina do Estado só pode ser assegurada, desde que o Estado funcione no modo do biopoder, pelo racismo. (FOUCAULT, 2005, p.306)

Longe de ser uma dinâmica apenas brasileira, a construção da raça, e dentro desta, do negro enquanto "raça" subalterna, é, de acordo com as análises de Achille Mbembe, "produto de uma máquina social e técnica indissociável do capitalismo, da sua 
emergência e globalização" (MBEMBE, 2014, p. 19). De fato, a construção do outro como não semelhante e como ameaçador deu-se em diferentes fases e diferentes formas de desenvolvimento do capitalismo, tendo encontrado na colônia e na escravidão o seu auge, considerando a imensa quantidade de vítimas e a extensão dos fenômenos no espaço e no tempo. Paralelamente ao desenvolvimento do capitalismo e profundamente interligado com este, Estados-Nações ocidentais, euro-americanos, construíram o próprio imaginário, a própria identidade através de um sentimento de pertencer a um dado lugar claramente excludente. Nesta visão o outro, quem vem de longe, fala uma outra língua, tem outra religião, etc. não é apenas diferente, mas ameaçador para a própria vida dos indivíduos incluídos dentro da norma, e por isso tem que ser aniquilado, visão esta que teve sua atuação concreta na lógica que sustentou conflitos bélicos como os dos Balcãs durante toda a década de noventa do século XX, apenas para citar um exemplo. Neste sentido, podemos entender tanto aquilo que Foucault identifica como sendo a segunda função do racismo, de tipo estritamente biológico, ou seja "a morte do outro, a morte da raça ruim, da raça inferior [...], é o que vai deixar a vida em geral [ou da Nação enquanto comunidade fechada] mais sadia; mais sadia e mais pura" (FOUCAULT, 2005, p. 305), tanto aquilo que Achille Mbembe chama de "racismo sem raça": "no intuito de aprimorar a prática da discriminação, tornando a raça conceitualmente impensável, faz-se com que cultura e religião tomem o lugar da «biologia»” (MBEMBE, 2014, p. 20).

Resumindo, para justificar dentro de uma organização política de tipo democrático a suspenção dos direitos, de forma que alguém passe a ser "matável", é preciso primeiramente fragmentar a população, estigmatizar uma parte dela e considerá-la como sendo um "inimigo". O racismo, que na atualidade vai além da raça passando a envolver classe social, culta e religião, opera então de forma funcional para esta fragmentação. A partir desta dinâmica seria assim possível explicar o altíssimo percentual de jovens negros mortos a cada ano no Brasil, os números de mortos devido às ações policiais e à baixíssima taxa de casos de homicídios resolvidos pela justiça. Percentual ainda menor se se considera aqueles casos de assassinato que envolvem diretamente os policiais:

A maior parte dos casos envolvendo policiais é arquivada ao chegar ao Ministério Público, que muitas vezes ataca procedimentos de exceção como quebra de sigilo e invasão de domicílio. Em uma pesquisa na qual avaliou trezentos processos de óbitos por intervenção policial, o delegado Orlando Zaccone identificou que $99 \%$ desses autos foram arquivados pelo MP em menos de três meses. [...] Segundo ele, a condição de vida de quem morreu, o local onde se deram os fatos ou a existência ou não de antecedentes criminais já são suficientes para que 
o Ministério Público identifique a morte como legítima [...]. De acordo com pesquisa realizada pelo Ministério de Justiça em 2009, 44\% dos brasileiros concordam com a máxima que diz que 'bandido bom é bandido morto"". (MENA, 2015)

Como a figura do Homo Sacer no direito romano ${ }^{6}$, negros, pobres, periféricos, às vezes com antecedentes criminais - mas nem sempre, como no caso tristemente famoso do pedreiro Amarildo Dias de Souza - são assim matáveis, sem que o assassino responda perante a lei pelo delito, já que tais existências representariam uma ameaça à sociedade, ao modelo burguês etnocêntrico, isto é, ocidentalocêntrico dominante.

No entanto, uma outra pergunta aparece-me como urgente, depois de ter discutido a lógica e o funcionamento do biopoder nas democracias modernas. Ou seja: como esse uso indiscriminado do poder soberano sobre determinados grupos de cidadãos, embora justificado pelo Estado de Exceção, possa ser efetivamente aceito e até incentivado "bandido bom é bandido morto" - para o restante da população?

De fato, as mortes violentas, os corpos atormentados e privados dos direitos básicos são apenas uma das tantas faces através do qual opera o biopoder, a ponta de um iceberg, poder-se-ia dizer. Existe na contemporaneidade uma continuidade efetiva dos paradigmas que marcaram a época colonial. Tal continuidade dá-se na fragmentação do espaço urbano, com as periferias - territórios de exceção - que vivem uma constante violação dos direitos de cidadania, vigiadas pelo braço mais violento do poder do Estado, o militar, e na fragmentação da população entre quem mora nesses territórios "inimigos" - a classe trabalhadora, negros e pobres - e o resto dos cidadãos. No entanto, para sustentar tal fragmentação, para torná-la aceitável é preciso invisibilizar aquela população sem direitos, e construir um discurso que justifique o estado de exceção.

No artigo "Os mecanismos midiáticos que livram a cara dos crimes das polícias militares no Brasil"' (2015), Laura Capriglione ressalta a relevância do papel desenvolvido pela mídia e evidencia alguns elementos que participam da fragmentação racista do espaço urbano e da população. Dois destes remetem diretamente para a condição de Homo Sacer, e para o uso indiscriminado da violência contra a vida nua, contra corpos sem direitos: a manipulação da narrativa, "dotada de uma imensa assessoria de imprensa, a

\footnotetext{
${ }^{6}$ Homo sacer, ou homem sagrado, ou seja, homem à espera de julgamento divino é, dentro do direito romano aquela condição, filha de uma pena, atribuída aos indivíduos cuja conduta colocaria em risco a pax deorum, ou seja, a aliança e a amizade entre as divindades e a civitas. Tal condição significa o completo abandono do culpado, cujo crime não pode ser julgado pela lei romana nem pelos homens, mas só pelos deuses. O Homo Sacer torna-se assim um homem matável - quem o matar não vai responder pelo crime de homicídio- já que a sua pena, no caso a morte, foi decidida justamente pelas divindades.
} 
Polícia Militar e a Secretaria de Segurança Pública fabricam suas "verdades" contra famílias pobres, desassistidas e desesperadas pela dor e pelo medo" (CAPRIGLIONE , 2015, p. 58), e a culpabilização da vítima, que extraída de qualquer contexto afetivo, familiar e de vizinhança reduz-se à condição de "Bandido absoluto" na maior parte das vezes, nem nome o morto possui nos registros"(Idem). As vítimas são, portanto, completamente invisibilizadas. Elas não têm meios, não tem recursos, portanto não tem voz no campo do debate democrático. Desprovidas de humanidade, são apenas objetos à deriva.

Como é notório, para Gayatri Spivak, dentro da lógica da colonização, a ausência de voz, da possibilidade de falar e ser ouvido, é de fato a única condição política e social do subalterno (SPIVAK, 2014). Essa falta de voz liga-se ao papel degradado e ameaçador que o colono projeta, como uma sombra essencialista à qual é impossível fugir, sobre as culturas colonizadas. Escreve Fanon:

A sociedade colonizada não é apenas descrita como uma sociedade sem valores. Não basta ao colono afirmar que os valores desertaram, ou melhor, jamais habitaram o mundo colonizado. O indígena é declarado impermeável à ética, ausência de valores, como também negação de valores. É, ousemos confessá-lo, o inimigo dos valores, neste sentido é o mal absoluto. (FANON, 1961, pp. 30/31)

No caso particular do Brasil, uma leitura diacrônica da historiografia nacional deixa transparecer o status de inferioridade, entre "negação de valores", reificação e ausências, atribuído às subalternidades - aos povos nativos e aos negros - levados no solo americano pelas rodas sangrentas do tráfico negreiro. Em "Colonização, miscigenação e questão racial: notas sobre equívocos e tabus da historiografia brasileira", Ronaldo Vainfas reconstrói as etapas da historiografia, desde metade do século XIX até final do século XX, no que diz respeito ao lugar do negro e do índio dentro do discurso sobre a nação brasileira. Tirando algumas exceções - dentro das quais insere-se o discurso ambíguo e "pacificador" de Gilberto Freyre em Casa Grande \& Senzala - Vainfas demostra como as subalternidades, e em particular os negros, sempre foram representados ou numa visão que reforçava os estereótipos coloniais ou, contra essa mesma imagem, como vítimas passivas da exploração. De qualquer forma, a participação ativa na construção da cultura foi sempre ou negada ou negligenciada, reforçando assim diretamente ou indiretamente a reificação do outro. Isto é, o outro enquanto objeto.

Perpetrar tal visão é, de fato, fundamental para tornar aceitável a condição de Exceção necessária ao poder soberano para exercitar seu direito de matar sobre os corpos 
dos excluídos. Em Necropolitics, texto fulcral para as minhas reflexões, devido às ligações entre biopolítica, poder soberano e organização da vida na colonial e na plantation, Achille Mbembe afirma que "sovereignty meant occupation, and occupation meant relegating the colonized into a third zone between subjecthood and objecthood". (MBEMBE, 2003, p.19)

Este status, entre sujeito e objeto é a conditio sine qua non para aquilo que Mbembe chama de ocupação colonial na modernidade tardia. Em Necropolitics, depois de ter abordado através de Michel Foucault a noção de biopolítica - e tê-la, num certo sentido, invertida já que biopolítica seria o controle exercido pelo poder sobre a vida, enquanto necropolítica apontaria pelo controle e pelo uso da morte como funcional para o poder - e as suas atuações na colônia e na vida da plantation, no capítulo chamado "Necropower and Late Modern Colonial Occupation", Achille Mbembe debruça-se sobre aquilo que ele considera um exemplo de ocupação colonial contemporânea: a franja de Gaza, na Palestina. Fragmentação da população e do espaço urbano seria, para Mbembe, uma das dinâmicas principais da ocupação colonial na modernidade.

Under these circumstances, colonial occupation is not only akin to control, surveillance, and separation, it is also tantamount to seclusion. It is a splintering occupation, along the lines of splintering urbanism characterized of late modernity (suburban enclaves or gated communities). [...] Under condition of vertical sovereignty and splintering colonial occupation, communities are separated across yaxis. This leads to a proliferation of the sites of violence. (MBEMBE, 2003, pp. 28/29)

A cidade contemporânea, com seus espaços marcados pelo uso indiscriminado da violência - violência sobre os corpos, mas também epistêmica, na invisibilização do discurso do outro -, ocupados pelas polícias através de intervenções baseadas em estratégias de tipo militar, tornar-se-ia então um lugar à mercê dos paradigmas contemporâneos da ocupação colonial.

\section{De malandros e marginais: Cidade de Deus, de Paulo Lins}

No seu artigo supracitado, sobre os mecanismos da mídia para amenizar os assassinatos cometidos pelo poder na atualidade brasileira, Laura Capriglione aponta para um outro elemento fundamental, ou seja, a hiper-representação da violência nos programas televisivos, em particular nos "sensacionalistas vespertinos". Capriglione, 
baseando-se nos depoimentos do tenente-coronel da reserva da Polícia Militar de São Paulo, Adilson Paes de Souza, evidencia como esses programas acabam incentivando a violência enquanto são avidamente consumidos dentro dos quartéis (CAPRIGLIONE, 2015). Por outro lado, tais imagens têm também o efeito de anestesiar o espectador perante o horror, sobretudo quando este afeta corpos sem rosto, sem nome, sem voz, todos aqueles corpos sobre os quais o poder soberano, para legitimar a Exceção, construiu, projetou a sombra de uma alteridade privada de valores, ameaçadora para a ordem constituída.

Está-se aqui perante de um fenômeno que tem proporções globais, não sendo, portanto, peculiar ao contexto do Brasil contemporâneo. De fato, a centralidade da violência na vivência do espaço urbano reflete-se e encontra expressão constante tanto na proliferação de imagens de horror caraterística da contemporaneidade, propagandeadas e até banalizadas pelos mass media, quanto em muita parte da produção artística contemporânea. No seu célebre texto Regarding de Pain of Others (2003), Susan Sontag afirma:

As everyone has observed, there is amounting level of acceptable violence and sadism in mass culture: films, television, comics, computer games. Imagery that would have had an audience cringing and recoiling in disgust forty years ago is watched without so much as a blink by every teenager in the multiplex. Indeed, mayhem is entertaining rather than shocking to many people in most modern cultures. (SONTAG, 2003: 90)

Vivida, observada no cotidiano das metrópoles contemporâneas ou representada pela televisão e pelo cinema, a violência configura-se, portanto, como um elemento fulcral da contemporaneidade urbana e da organização do poder. Tal situação, por si, ofereceria uma possível chave de leitura para pensar a relevância que o horror adquire também na literatura, seja enquanto tema ou plano de fundo - nas suas interligações com o espaço urbano: a cidade como lugar de conflito, um dos tópicos de muita literatura contemporânea - seja enquanto elemento fulcral em escritas moldadas pela experiência direta da dor e dos conflitos.

No entanto, perante a continua banalização do horror, funcional às dinâmicas violentas do poder, torna-se necessário investigar a origem, a proveniência dessas imagens de violência na contemporaneidade. Em $O$ espectador emancipado, e em particular no capítulo “A imagem intolerável”, Jacques Rancière investiga justamente 
essa produção e banalização do horror, daquilo que ele chama de "imagem intolerável" na realidade contemporânea. Escreve o Filosofo francês:

Se o horror está banalizado, não é porque vemos imagens demais. Não vemos corpos demais a sofrerem na tela. Mas vemos corpos demais sem nome, corpos demais incapazes de nos devolver o olhar que lhes dirigimos, corpos que são objetos de palavra sem terem a palavra. $\mathrm{O}$ sistema de informação não funciona pelo excesso de imagens, funciona selecionando seres que falam e raciocinam, que são capazes de «descriptar» a vaga de informações referentes às multidões anônimas. A política dessas imagens consiste em nos ensinar que não é qualquer um que é capaz de ver e falar. (RANCIÈRE, 2012, p. 95)

O horror que vemos reproduzido pela mídia ou por algumas expressões artística de fato diz respeito a esses corpos sem nome. Envolve toda aquela humanidade que vive no espaço reservado para o outro - no contexto urbano, a periferia, a favela o gueto -, relegado pelo poder soberano à condição de Homo sacer. Tais indivíduos excluídos não têm representatividade na mídia, e não têm voz na arte nem na literatura-considerando a voz na acepção proposta por Rancière, como algo que "também faz parte do processo de construção da imagem. É a voz de um corpo que transforma um acontecimento sensível em outro, esforçando-se por nos fazer «ver» o que ele viu, por nos fazer ver o que ele nos disse" (RANCIÈRE, 2012, p. 92). Tomando como exemplo o corpus de obras que constitui a literatura brasileira contemporânea, em particular aquela publicada pelas editoras maiores e que, por isso, tem uma divulgação mais ampla, podendo então ser consideradas como aquelas obras que participam na construção de um "senso comum"7, a ausência da voz subalterna aparece como evidente. Em uma pesquisa desenvolvida na Universidade de Brasília por um grupo de estudo coordenado por Regina Delcastagnè sobre a Personagem do romance brasileiro contemporâneo entre 1990 e 2004 aparece de forma evidente que a grande maioria das personagens são homens, brancos e heterossexuais. Esses dados correspondem por completo com os relativos aos dos próprios escritores desses romances: na maioria homens, brancos, heterossexuais moradores dos bairros mais abastados do eixo Rio de Janeiro/São Paulo (DELCASTAGNÉ, 2005). Ou seja, aqueles sujeitos que, por outro lado, não aparecem mencionados nas estatísticas da Mapa da violência.

\footnotetext{
${ }^{7}$ A noção de "senso comum" provém do arsenal conceitual de Antonio Gramsci e dos seus estudos sobre a hegemonia. No entanto, estou me referindo agora à definição oferecida por Jacques Rancière: "um senso comum é, acima de tudo, uma comunidade de dados sensíveis: coisas cuja visibilidade considera-se partilhável por todos, modos de percepção dessas coisas e significados também partilháveis que lhes são conferidos. É também a forma de convívio que liga indivíduos ou grupos com base nessa comunidade primeira entre palavras e coisas. (RANCIÈRE, 2012, p. 99)
} 
Voltando às reflexões de Jacques Rancière, pode-se, portanto, afirmar que o problema não é a imagem por si, mas tudo aquilo dentro do qual a imagem está envolvida, sua proveniência, sua lógica e função dentro de um determinado discurso:

O problema não é saber se o real desses genocídios pode ser posto em imagens e em ficção. É saber como é posto e qual espécie de senso comum é tecido por esta ou aquela ficção, pela construção desta ou daquela imagem. É saber que espécie de ser humano a imagem nos mostra e a que espécie de ser humano ela é destinada [...]. As imagens da arte não fornecem armas no combate. Contribuem para desenhar configurações novas do visível, do dizível e do pensável e, por isso mesmo, uma paisagem nova do possível. (RANCIÈRE, 2012, p. 100)

No âmbito da literatura mais recente, floresceram as representações da violência urbana baseadas em estéticas que oscilam entre o realismo e o documento etnográfico. Tal interesse pode ser lido, de acordo com as análises de Hal Foster, dentro da mais ampla atenção da arte contemporânea pelo trauma - ao nível individual e coletivo, isto é: a história como trauma - e pela abjeção. Atenção que, segundo o autor, seria motivada por diversos fatores, tanto de caráter estéticos quanto puramente contextuais:

Porque hoje esse fascínio pelo trauma, essa inveja da abjeção? É certo que existem motivos na arte e na teoria. Como foi sugerido há uma insatisfação com o modelo textualista da cultura e com a visão convencionalista da realidade -como se o real, reprimido no pósmodernismo pós-estruturalista, tivesse retornado como traumático. [...] Mas existem forças poderosas em ação também em outras partes: o desespero ante a persistência da crise da Aids, doenças e mortes invasivas, pobreza e crime sistêmicos, o bem-estar social destruído, inclusive o contrato social rompido [...] A articulação dessas diferentes forças é difícil; em conjunto, no entanto, elas estimulam a preocupação contemporânea com o trauma e a abjeção. (FOSTER, 2014, p. 158)

A cidade contemporânea, com seu histórico de conflito e exploração assim como com o seu presente fortemente marcado pelo perpetuar-se das dinâmicas que caracterizaram a modernidade colonial - como a subalternização de indivíduos com base na raça, a fragmentação da população e do espaço urbano, e a ocupação violenta desses espaços -, desencadeia no artista a urgência de relatar a violência, o interesse pelas lógicas de poder subjacentes, e pelas realidades particulares vítimas deste sistema. E desencadeia também, nas próprias vítimas a necessidade da fala, a insurgência da própria voz silenciada pelo discurso oficial. De tal forma, a arte ultrapassa as fronteiras da teoria e da estética para passar a ser pensada dentro de campos mais amplos, o da cultura, antes 
domínio da antropologia (FOSTER, 2014), e o político, enquanto sugerem uma outra possibilidade na partilha do sensível (RANCIÈRE, 2009).

Desta dinâmica resulta, por um lado, o interesse do artista politicamente engajado, chamado por Hal Foster "o artista como etnógrafo", pelo outro cultural - no caso das representações literárias da violência urbana, o marginal e o periférico. Por outro lado, o mais significativo processo de afirmação da própria voz do "outro" dentro do universo artístico e literário. Deste movimento profundamente complexo - como se aproximar do outro sem projetar nele a sombra do próprio lugar hegemônico - resulta uma arte amparada no real que busca um valor documental. No segundo caso, a questão central pode-se tornar justamente o como contar a própria história, como construir outras realidades, outras formas de senso comum, uma vez que a perspectiva das vítimas sempre foi brutalmente silenciada pelo poder.

De qualquer forma, se se considerar as representações literárias da violência urbana nas metrópoles contemporâneas, seja por partes de indivíduos postos à margem da sociedades seja por escritores considerados "etnógrafos", pode-se afirmar, de acordo com Hal Foster, que "chamar nosso mundo de pós-colonial é mascarar a persistência de relações coloniais e pós-coloniais; é também ignorar que, assim como sempre existiu um primeiro mundo em cada terceiro mundo, sempre existiu um terceiro mundo em cada primeiro mundo" (FOSTER, 2014, p. 199). Um exemplo deste interesse da literatura pela violência urbana como elemento fulcral na vivência contemporânea, encontra-se dentro do corpus de textos que compõe a mais recente literatura brasileira ${ }^{8}$. Nesse âmbito, um caso significativo para pensar tanto o papel da escrita e do escritor quanto a continuidade das dinâmicas coloniais na atualidade é, sem dúvida, o romance Cidade de Deus, (1997) de Paulo Lins.

De fato, Cidade de Deus têm como foco de interesse os conflitos que marcam a vivência em áreas que pertencem à periferia urbana: o conjunto habitacional Cidade de Deus, na zona oeste de Rio de Janeiro. O próprio autor encontra-se pessoalmente ligado aos lugares representados nos próprios romances: Paulo Lins foi criado em Cidade de Deus, tendo se mudado para lá aos oito anos de idade, e tendo residido no conjunto habitacional (ou neofavela, segundo a definição do próprio Lins) até o grande sucesso do romance, que lhe deu as condições necessária para sair de Cidade de Deus. Partindo de

\footnotetext{
${ }^{8}$ Para pensar a violência na literatura brasileira e a cidade como locus de conflito nas produções mais recentes, veja o ensaio "Linguagens contemporâneas da violência", de Karl Erik Schøllhammer (2014).
} 
uma aproximação entre o personagem de Buscapé e o próprio Paulo Lins, João Camillo Penna afirma:

O personagem de Buscapé, o fotógrafo que escapou de ser engolido pelo narcotráfico - baseado em José Wilson dos Santos, outro morador de Cidade de Deus, que trabalha hoje em dia como fotógrafo profissional - é um duplo do autor. Com Paulo Lins, a literatura brasileira provou ser uma poderosa arma subjetivante, capaz de "salválo" do enredo determinista de pobre morador de Cidade de Deus, que define, por outro lado, a carreira de todos os personagens da saga que narrava, como destino de exceção. (PENNA, 2013, p. 285)

A estrita proximidade do autor com o contexto representado em Cidade de Deus permitiu ao próprio conhecer não apenas a realidade, mas também algumas das personagens e das estórias que aparecem no romance. Escreve Lins numa entrevista publicada na revista Veja:

Era doido. Aconteceu várias vezes de eu estar romanceando um personagem e ele passar na frente lá de casa, em carne e osso. Eu saía correndo, com meu gravadorzinho de bolso, e ia atrás. Comecei procurando personagens amigos, com quem cresci, pois na Cidade de Deus a relação bandido-morador, bandido-cidadão, bandido-nãobandido é distante. [...]. Os personagens reais frequentavam minhas noites e o meu dia-a-dia. Na hora de cortar um ou outro, eu tinha pesadelos. Sonhava com todos os bandidos vestidos de Exu. Ao acordar, acabava colocando pedaços do sonho no livro. Como eu não tinha computador, o meu medo era deixar alguém sem final (LINS, 1997, p. 116/118)

$\mathrm{O}$ romance foi pensado e escrito em um período de aproximativamente oito ou nove anos, entre o final da década de oitenta e o princípio da de noventa. Naquela época, justamente por ser um morador da comunidade, o autor acompanhou como pesquisador e informante os projetos "Crimes e Criminalidades nas classes populares" e "Justiça e classes populares", ambos coordenados pela antropóloga Alba Zaluar, que ao começar o trabalho de campo, percebeu "que o abismo entre a acadêmica branca de classe média e os «nativos» que entrevistava era tão vasto que havia filtragem substancial da informação, tornando o seu trabalho de campo completamente impossível"(PENNA, 2013, p. 284). Desta forma, com a escrita de Cidade de Deus, Paulo Lins transforma-se progressivamente de objeto de pesquisa antropológica em sujeito que encena, reapresenta, através da escrita ficcional, o próprio universo marginalizado pelas lógicas do poder. Esta posição dupla do autor faz de Cidade de Deus "uma aventura artística incomum”, como foi definido o romance por Roberto Schwarz (1997). 
A construção da obra, num certo sentido, manifesta a distância (ou a falta de distância) entre o autor e a matéria narrada. Em Cidade de Deus a escolha de um narrador absolutamente onisciente, cujo ponto de vista é ilimitado podendo assim escolher qualquer perspectiva, parece sugerir a inclusão completa do autor empírico dentro da comunidade por ele representada. Desta forma, Paulo Lins consegue oferecer um panorama amplo da organização da vida social na favela: ao lado das histórias dos bandidos mais influentes que dominam os três capítulos, Cidade de Deus apresenta um mosaico de acontecimentos, anedotas e elementos que pertencem à cultura popular e ao cotidiano da comunidade e que se sobrepõem dando à narrativa um ritmo às vezes frenético. Desta forma, sem perder o foco sobre a vida violenta do subúrbio carioca, Paulo Lins consegue manter um pouco da pluralidade que caracteriza os bairros populares do Rio de Janeiro: trabalhadores, estudantes, mães solteiras e meninos de rua misturando as próprias aspirações e as próprias ambições com os caminhos de bichos-soltos, criminais, traficantes de droga e as balas dos policiais. A este ritmo frenético opõe-se um plano de fundo constituído por um enredo essencialmente monótono onde sequências, cenas e capítulos se sobrepõem tendo essencialmente o mesmo leitmotiv, caraterizado pelo surgimento, nos personagens, de necessidades -geralmente ganhar dinheiro para satisfazer a fome ou o vício - , pelo crime enquanto único caminho possível para satisfazer tais necessidades, e pela fuga da polícia. Escreve Roberto Schwarz:

Em plano menos palpável há a quase-padronização das sequências, sinistramente monótonas em sua variação. Depois de uma ou outra droga ou diversão vem a saída para um assalto, [...]. Os passeios com propósito de distração, para jogar bola na praia ou armar rolo numa festa, depois de alguma confusão tendem para o mesmo desenlace, o que é uma das linhas evolutivas amargas do livro. Depois vem a fuga, a pé, de ônibus, em carro roubado ou táxi, e o entocamento para passarem as 24 horas do flagrante. Trancados num quarto qualquer, os "bichos-soltos" tomam leite ou precisam de mais droga para recuperar a calma e dormir. (SCHWARZ, 1997)

Tal estratégia representativa, que favorece a descrição de personagens, situações e acontecimentos particulares costurados um atrás do outro, em detrimento de uma narração homogênea, é de fato uma marca caraterística da obra. A urgência de contar, de relatar as tantas vivências plurais faz como que o momento descritivo prevaleça sobre o narrativo. $\mathrm{O}$ enredo foi, de fato, já oferecido pela realidade, ao autor cabe aqui apresentála, dar-lhe uma voz que possa ser ouvida -objetivo que o romance, pelo grande sucesso de público, alcançou de forma magistral. 
A realidade que Cidade de Deus encena, carateriza-se por transformações e profundas mudanças: no conjunto habitacional, situado próximo a uma das áreas de maior crescimento e valor imobiliário de todo o Brasil, a Barra da Tijuca -área que recebeu recentemente grandíssimos investimentos e que foi teatro de violentas remoções forçadas devidas à especulação imobiliária pré-Jogos Olímpicos ${ }^{9}$ - a partir de 1966 mudaram-se mais de 3500 famílias, embora a falta das condições habitacionais básicas. Desde cedo, a atenção da imprensa participou da estigmatização da população que aí residia enquanto a polícia intervinha nos modus operandi questionados no capítulo anterior. Em "Cidade de Deus -memória e etnográfica em Paulo Lins", Paulo Jorge Ribeiro escreve:

A população que lá vive desde aqueles tempos fora acostumada a um cotidiano de tragédias e a estar nas páginas dos jornais cariocas e nacionais por suas cenas de violência. Já na década de 70, a batalha pelo tráfico de drogas entre Zé Pequeno e Mané Galinha tomou conta dos noticiários [...]. Na década posterior, o assassinado de Marcellus Gordilho [...] mobilizou a população, as forças governamentais, a sociedade civil e também a imprensa carioca em um dos primeiros momentos de demonstração significativa de exposição pública do processo pernicioso que a violência cada vez mais assumia no Rio de Janeiro. Já na década de 90 [...] um cinegrafista amador filmou cenas nas quais PMs espancavam indiscriminadamente trabalhadores [...] (RIBEIRO, 2000, p. 74/75)

Acompanhando o desenvolvimento do conjunto habitacional na zona oeste carioca durante três décadas - de 1960 a 1980 - , Paulo Lins representa o momento em que a entrada da cocaína nas favelas reconstituiu o inteiro sistema da criminalidade no Rio de Janeiro. De fato, o romance, composto por três capítulos, acompanha justamente a transformação do criminoso que cometia assaltos e pequenos roubos, na década de sessenta, no narcotraficante da atualidade:

Seu sonho de ser dono de Cidade de Deus estava ali, vivo, completamente vivo, realizado, com extrema saúde ao seu lado do sofá. [...] O negócio agora era botar tóxico bom e barato em suas bocas-defumo, ter sempre Brizola para quem quisesse, porque, apesar de não vender muito, a cocaína era cara, rendia um dinheiro bom. [...] Traficar, isso que estava na onda, isso que estava dando dinheiro (LINS, 1997, p. 241)

\footnotetext{
${ }^{9}$ As remoções forçadas são de fato mais uma expressão do exercício do poder soberano sobre a vida nua, na medida em que as populações mais carentes encontram-se arbitrariamente expropriadas dos direitos de propriedades e de moradia. Segundo David Harvey em Cidades Rebeldes, tal dinâmicas vincula-se aos desenvolvimentos globais do capitalismo e encontra paralelos em diferentes partes do globo, na Índia, na China e no Brasil, entre outros. Para um estudo dos processos que caracterizaram as recentes remoções e abusos na zona oeste do Rio de Janeiro, veja-se: Remoções no Rio de Janeiro olímpico, de Lucas Faulhaber e Lena Azevedo.
} 
Neste sentido Cidade de Deus reproduz um momento já presente em algumas obras artísticas e literárias brasileiras já a partir das décadas de setenta e oitenta: a passagem da figura do malandro -entendido, segundo Antonio Candido, como síntese possível entre os pólos da ordem e da desordem (1970) - , a do marginal. Em "A violência como desafio para a literatura brasileira contemporânea", ao discutir sobre as personagens que povoam a ficção de Rubem Fonseca, Karl Erik Schøllhammer resume perfeitamente o movimento construído por Paulo Lins na passagem entre a segunda parte do romance "A história de Bené" e a explosão de violência que caracterizou a guerra entre facções rivais da última parte de Cidade de Deus:

Percebemos a emergência de um novo tipo de bandido [...]. Esse novo bandido é jovem, malnutrido, com dentes ruins, analfabeto e sem opções, como milhões de brasileiros nascidos nas décadas de 1970 e 1980. Mora numa favela ou na periferia da cidade, e muito jovem passa a integrar as quadrilhas do tráfico de drogas, no início trabalhando apenas como avião ou fogueteiro. Ainda adolescente ganha uma arma, e com a arma vêm um tênis novo, poder aquisitivo, garotas, poder na comunidade e uma expetativa de vida cada vez mais curta. $\mathrm{O}$ novo bandido é resultado de uma nova ordem do crime em que não predomina mais o mercado restrito da maconha, puxado pelo malandro, mas o mercado da cocaína, de circulação financeira muito maior, garantido por quadrilhas fortemente armadas, que passam a construir o poder informal nos morros da cidade. (SCHØLLHAMMER, 2013, p.58)

De acordo com as estatísticas relativas ao último Mapa da violência, também os mortos em Cidade de Deus são extremamente e tristemente jovens, "na situação chega a parecer lógico que chefes de 17 anos designem soldados de 12 ou 10, menos vigiados, para a tarefa de fuzilar o dono de outra boca de fumo, que terá 18" (SCHWARZ, 1997). Todos deixados morrerem na mais completa ausência de perspectivas num contexto onde o poder público só se manifesta com as armas dos policiais, presenças que, justamente como nos contextos coloniais referidos e discutidos por Frantz Fanon, marca profundamente a subjetividade dos oprimidos. Uma passagem emblemática do romance, por ser uma das pouquíssimas ações que não tem como plano de fundo a favela ou um presídio, mostra como esse contato constante entre os marginalizados e a expressão mais violenta do poder, a polícia, afeta as subjetividades. O personagem Fabiano, indo pelo bairro da classe alta carioca, o Leblon, aparece vislumbrado pela possibilidade de uma vida sem as carências da pobreza, até cruzar com a polícia. A simples presença de uma patrulha desperta em Fabiano a crua realidade da sua condição, e o crime retoma posse das páginas do romance: 
A agitação do Baixo Leblon encantou Fabiano. [...] Ficaram olhando as cores da noite que se dava ali, talvez aquilo fosse realmente a normalidade da vida, gente jovem como eles tomada por uma felicidade que eles havia muito tempo não sentiam. Os carros, as roupas, as luzes... Acharam que nada no mundo era pior do que a pobreza, nem a mesma doença. Pararam no sinal e um menino negro ofereceu-lhes um jornal já de domingo [...]. Numa esquina, uma patrulha parada; de repente, a realidade deles estava ali presente, mas dessa vez de outra forma, o objetivo deles estarem ali tomou corpo novamente quando viram o 38 na cintura do policial encostado à viatura. (LINS, 1997, p. 465)

As fronteiras dentro das quais se movem os personagens do romance são, de fato, as que delimitam o conjunto habitacional. O mundo fora de Cidade de Deus aparece apenas enquanto lugar onde cometer crimes e não intervém ativamente na narração, comportando-se exclusivamente como plano de fundo. Desta forma, Paulo Lins consegue reproduzir a fragmentação espacial e social operada pelo poder, subvertendo, porém, os eixos: no romance o que importa é exclusivamente aquilo que acontece dentro da comunidade. $\mathrm{O}$ bandido tem nome, história - frequentemente trágica desde a infância enquanto as vítimas que moram fora da comunidade, que pertencem à classe média ou alta não tem nenhuma conotação específica. Como afira Schwarz:

Literariamente, a órbita limitada funciona como força, pois ela dramatiza a cegueira e a segmentação do processo: em seu ramo, reservado aos desvalidos, os chefes de bando não deixam de ser potências, criaturas que entre outras coisas usaram a cabeça e aprenderam lições duríssimas, isso sem falar na incalculável tensão nervosa que suportam a todo momento. Nem por isso deixam de ser pobres diabos, que morrem como moscas, longe da opulência que nalgum lugar o tráfico deve proporcionar. (SCHWARZ, 1997)

No entanto, como o próprio romance nos informa, aquilo que acontecia dentro da favela ultrapassava, graças à imprensa, as suas fronteiras passa se tornar de conhecimento público, colaborando para construir a estigmatização social funcional à estratégia do poder de fragmentação do espaço urbano que afeta ainda hoje a comunidade:

A Cidade de Deus, tornou-se o lugar mais violento do Rio. O conflito entre Zé Pequeno e Mané Galinha fora qualificado como guerra. Guerra entre quadrilhas de traficantes. A rotina atroz dos combates passou a povoar as páginas policiais e amedrontar os alheios, só informados pelos noticiários. As edições se esgotavam ainda cedo, a audiência dos telejornais e dos programas especializados no tema subiram muito na favela. (LINS, 1997, p. 429) 
Como para Pasolini no seu recurso à Comédia de Dante, a miséria é um limbo dentro do qual perambulam os corpos atormentados pelas violências endêmicas. Perante dessas situações precárias, os casos de negligência do poder público - ou seja, a lógica do “deixar morrer" - são, no romance, inúmeros, já que a própria estrutura da obra como sendo um mosaico de estórias desgraçadas favorece o aparecimento de exempla.

Refletindo acerca da cidade de Salvador da Bahia a partir da leitura do romance Jubiabá, de Jorge Amado, no artigo "Cenas e cenários da cidade negra" Eneida Leal Cunha oferece uma perspectiva estimulante para pensar a marginalidade e o crime em Cidade de Deus no seu potencial político de emancipação perante a ordem colonialista e escravagista que sustenta ainda hoje a organização do poder. Afirma Cunha:

Consequência da orfandade, do abandono ou da fuga ao convívio familiar, a vida na rua é, por um lado, uma alternativa à ausência de perspectivas para esse contingente que descende de negros pobres e livres, mas é, por outro, a libertação das funções subservientes e serviçais nos sobrados ou da subordinação aos "mestres de ofício", as duas instituições formativas destinadas aos jovens pobres e negros, as quais guardam completa fidelidade à ordem escravagista: na relação de pertencimento a um senhor, no disciplinamento corporal, na exploração não-remunerada do trabalho. A sobrevivência nas ruas exige estratégias de organização e defesa, das quais surgem os bandos - ou quadrilhas, como então se dizia — de meninos e meninas. (CUNHA,199, p.133)

Em Cidade de Deus a violência, as dinâmicas hegemônicas do poder assim como as estratégias de sobrevivência estão encenadas de maneira direta, sem alguma forma de mediação possível, ao contrário da conciliação pacífica propiciada segundo António Candido pela chamada "dialética da malandragem": marginal remete inseparavelmente à condição de Homo Sacer e, portanto, sua sobrevivência não pode ser negociada. No romance as situações descritas, através de uma língua, a das classes populares, fortemente expressiva enquanto conserva, nos recursos às expressões do cotidiano, às gírias, aos traços típicos da oralidade, toda uma vivência marcada pelo sofrimento, conseguem atingir diretamente o leitor que vai sendo empurrado para um questionamento da própria posição - do próprio universo, da própria visão de mundo - de leitor/espetador perante os relatos do horror. Citando Paulo Jorge Ribeiro, "tudo agride em Cidade de Deus: as mortes, a violência gratuita, o descanso do poder público e da sociedade, os estereótipos, a perda de alguma aura, até mesmo o português falado pelas personagens” (RIBEIRO, 2000, p. 93).

No entanto, aquela literatura que constrói esse espaço nevrálgico da contemporaneidade, a cidade, tendo como centro gravitacional justamente a margem, ao 
subverter os paradigmas do poder -segundo os quais o que interesse são apenas os "centros" - , e ao fazê-lo através da própria voz dos sujeitos que habitam a margem, outrora silenciada, configura-se como um campo de intervenção e atuação política. A sobrevivência daqueles corpos desprovidos dos direitos de cidadania, representados por uma escrita que agride o leitor, constitue-se então como sendo um verdadeiro campo de resistência enquanto permite pensar outras realidades. Criar, de acordo com Rancière, "outras formas de senso comum, ou seja, outros dispositivos espaço temporais, outras comunidades de palavras e de coisas, formas e significados" (2012, p. 99). Isto é: fazer viver aquilo que era destinado a ser deixado morrer.

\section{Referências bibliográficas}

AGAMBEN, Giorgio. Lo stato d'eccezione. Milano, Bollati Boringhieri, 2003.

AGAMBEN, Giorgio. Homo sacer. Il potere sovrano e la nuda vita. Torino: Einaudi, 1995.

ALIGHIERI, Dante. La divina commedia. Milano: Mondadori. 2005.

BENJAMIN, Walter. Obras escolhidas: magia e técnica, arte e política. São Paulo: Ed. Brasiliense, 1994.

CANDIDO, Antônio. "Dialética da Malandragem: caracterização das Memórias de um sargento de milícias". In: Revista do Instituto de estudos brasileiros, no 8, São Paulo: USP, 1970, pp. 67-89.

CAPRIGLIONE, Laura. "Os mecanismos midiáticos que livram a cara dos crimes das polícias militares no Brasil”. In: AAVV. A violência policial no Brasil e os desafios para sua superação. São Paulo: Boitempo, 2015, pp. 56-60.

CLIFFORD, James. A experiência etnográfica. Rio de Janeiro: Ed. UFRJ, 1998.

CUNHA, Eneida Leal. "Ceneas e cenários da cidade negra". Semear, Rio de Janeiro, n.N.3, p. 129-138, 1999.

DELCASTAGNÈ, Regina. "A personagem do romance brasileiro contemporâneo". Estudos de literatura brasileira. N. 26, Brasília, Julho-Dezembro 2005, p. 13-71.

FANON, Frantz. Les damnés de la terre. Paris: François Maspero, 1961.

FAULHABER, Lucas. AZEVEDO, Lena. Remoções no Rio de Janeiro olímpico. Rio de Janeiro: Mórula, 2015.

FOSTER, Hal. O retorno do real. São Paulo: Cosac Naif, 2014.

FOUCAULT, Michel. "Aula de 17 de março de 1976”. In Em defesa da sociedade. São Paulo: Martins Fontes, 2005, p. 285-315.

GOMES, Renato Cordeiro. "A cidade, a literatura e os estudos culturais: do tema ao problema”. In: Ipotesis: revista de estudos literários. V.3, N.2, Juiz de Fora: UFJF, pp 19-30.

HARVEY, David. Cidades rebeldes. São Paulo: Martin fontes, 2014.

LINS, Paulo. Cidade de Deus. São Paulo: Companhia das Letras, 2002.

LEFEBVRE, Henri. The urban revolution. Minneapolis, University of Minnesota Press, 2003.

MENA, Fernanda. "Um modelo violento e ineficaz de polícia". In: AAVV. A violência policial no Brasil e os desafios para sua superação. São Paulo: Boitempo, 2015, pp. 
MBEMBE, Achille. "Necropolitics”. In: Public Culture, Duke University Press, 2003, p. 11-40.

MBEMBE, Achille. Crítica da razão negra. Lisboa: Antígona, 2014.

PENNA, João Camillo. Escritos de sobrevivência. Rio de Janeiro: 7letras, 2013.

PORTO-GONÇALVES, Carlos Walter. SILVA, Rodrigo Torquato da. "Da lógica do favor à lógica do pavor: um ensaio sobre a geografia da violência na cidade do Rio de Janeiro".In: FERNANDES, Ana. ROLNIK, Raquel. Cidades. Rio de Janeiro: Funarte, 2016.

RANCIÈRE, Jacques. A partilha do sensível: estética e política. São Paulo: Editora 34, 2009.

RANCIÉRE, Jacques. O espectador emancipado. São Paulo: Martins Fontes, 2012.

RIBEIRO, Luiz Cesar de Queiroz. "Prefácio". In: WACQUANT, Loïc. Os condenados da cidade. Rio de Janeiro: Revan, 2001.

RIBEIRO, Paulo Jorge. "Cidade de Deus-memória e etnografia em Paulo Lins". Lugar comum. N.11, Maio-Agosto 2000, p. 73-93.

SCHØLLHAMMER, Karl Erik. Cena do Crime: violência e realismo no Brasil contemporâneo. Rio de Janeiro: Civilização Brasileira, 2013.

SCHWARTZ, Roberto. "Uma aventura artistica incomum”. Folha de São Paulo. Disponível em: http://www1.folha.uol.com.br/fsp/1997/9/07/mais!/24.html. Ultimo acesso 15/12/2016.

SOARES, Luiz Eduardo. "Por que tem sido tão difícil mudra os políciais". In: AAVV. A violência policial no Brasil e os desafios para sua superação. São Paulo: Boitempo, 2015, pp. 27-32.

SONTAG, Susan. Regarding the pain of others. London: Penguin Book, 2003.

SPIVAK, Gayatry Chakravorty. Pode o subalterno falar?. Belo Horizonte: Editora da UFMG, 2010.

VAINFAS, Ronaldo. "Colonização, miscigenação e questão racial: notas sobre equívocos e tabus da historiografia brasileira". In: Tempo - Revista digital de história da Universidade Federal Fluminense. Vol. 8, Agosto 1999.

VELHO, Gilberto. "Violência e conflito nas grandes cidades contemporâneas". VII Congresso Luso-Afro-Brasileiro de Ciências Sociais. Atos do Congresso, 2004, p. 1-9.

WAISELFISZ, Julio Jacobo. Mapa da Violência 2016. Homicídios por armas de fogo no Brasil. Disponível em: http://flacso.org.br/files/2016/08/Mapa2016_armas_web.pdf. Ultimo acesso: $15 / 12 / 2016$

Data de Recebimento: 18/01/2018

Data de Aprovação: 14/08/2018 


\title{
Para citar essa obra:
}

FAZZINI, Lucas, Territórios de exceção: poder, espaço urbano, literatura. In: RUA [online]. Volume 24, número 2 - p. 461-487 - e-ISSN 2179-9911 - novembro/2018. Consultada no Portal Labeurb - Revista do Laboratório de Estudos Urbanos do Núcleo de Desenvolvimento da Criatividade.

http://www.labeurb.unicamp.br/rua/

Capa: detalhe da capa do livro Cidade de Deus, de Paulo Lins, $2^{a}$ edição. Tusquets Editores.

\author{
Laboratório de Estudos Urbanos - LABEURB \\ Núcleo de Desenvolvimento da Criatividade - NUDECRI \\ Universidade Estadual de Campinas - UNICAMP \\ http://www.labeurb.unicamp.br/ \\ Endereço: \\ LABEURB - LABORATÓRIO DE ESTUDOS URBANOS \\ UNICAMP/COCEN / NUDECRI \\ CAIXA POSTAL 6166 \\ Campinas/SP - Brasil \\ CEP 13083-892 \\ Fone/ Fax: (19) 3521-7900 \\ Contato: http://www.labeurb.unicamp.br/contato
}

